\title{
Mortality and Causes of Death in Inherited Antithrombin Deficiency
}

\author{
H. H. van Boven', J. P. Vandenbroucke', R. G. J. Westendorp' , F. R. Rosendaal' 2
}

From the 'Department of Clınıcal Epidemiology, University Hospital Leiden, and ${ }^{2}$ Hemostasis and Thrombosis Research Center, University Hospital Leiden, The Netherlands

\section{Summary}

To assess the contribution of inherited antithrombin deticiency to mortality, we investigated the causes of dedth in 14 familes with inherIted antithrombin deficiency Between 1830 and 1994, 86 of 266 famı ly members who had a probability of 05 or more for heterozygosity died The causes of death were obtaned for 58 of 66 deaths occurring between 1940 and 1994 Standardized motality ratıos (SMR) were calculated using mortality rates from the general population adjusted tor age, sex and calendar penod

The overall SMR was 090 from 1830 to 1994 (95\% C I 0 72-1 11) F1om 1940 untıl 199444 men and 22 women died (SMR = 109, 95\% C I 0 84-1 39, SMR men $=120,95 \%$ C I 087161 , SMR women $=$ 092,95\% C I 0 58-1 39) No excess mortality compared to the general population was found for cancer ( 14 deaths) or circulatory diseases (28 deaths) A slightly incieased mortality caused by respuatory diseases ( 7 deaths, SMR $=168,95 \%$ C I $068-347)$ seemed due to pneumonid (4 deaths, SMR $=286,95 \%$ C I 078732 ) Venous thromboembolic complications were listed once in association with a risk situation, and one other death could be attributed to fatal pulmonary embolism Cerebral hemorrhages were listed three tumes It could not be verified whether these hemorrhages were related to anticodgulant theiapy, the fiequency was slightly higher than the expected population figure (SMR $=149,95 \%$ C I $031-4$ 36) The mean age of death for all causes was 64 years, the two fatal thromboembolic episodes occuried at age 20 and 30 years

The data show that antithrombin deficiency is associated with a normal survival and a low risk of tatal thromboembolic events The use of long-teim anticoagulant treatment in asymptomatic individuals should be considered caretully in view of the greater risk of fatal bleeding associated with long-term anticoagulant prophylaxis

\section{Introduction}

Inherited antithrombin deficiency is an uncommon autosomal disorder associated with a tendency to venous thromboembolism In families with inherited antithrombin deficiency, (recurrent) thromboembolic episodes manitest in heterozygous members, with the tirst thiombosis usually occurring between 20-40 years of age (1) These epısodes mostly consist of venous thrombosis of the lower extremities and pulmonary embolısm, though sometimes thrombosis occurs at unusual sites such as cerebral and mesenteric veins These latter manifestations as well as

Correspondence to Dr FR Rosendaal, Department of Clinıcal Epidemıol ogy, University Hospital, Bulding 1 CO-P45, P O Box 9600, 2300 RC Lesden. The Netherlunds - Tel + 31715264037 , FAX Number + 31715248122 pulmonary embolısm can become life-threatening events and have been reported as fatal thromboembolic complications in some families (2)

We have already reported a study of overall mortality in 10 famlles with inheited antithrombin deficiency (3) It was found that inherited antithrombin deficiency did not appear to affect survival as compared with the general population Similarly, we found a normal life expectancy in families with another inherited risk factor for thrombosis, $1 \mathrm{e}$ protein $\mathrm{C}$ deficiency (4) Thus. although these genetic disorders increase the risk of thrombosis. it was concluded that they do not increase overall mortality

Although antithrombin deticiency may not lead to a noticeable number of excess deaths, it may still increase specific mortality anising from one or more causes It is conceivable that the overall mortality figures mask an increased number of deaths due to venous thrombosis We have therefore in the present study analyzed the causes of death in 14 Dutch famılies with inherited antithrombin deficiency with particular emphasis on causes related to thrombosis We compared the pattern of mortality to that expected in the general population in order to assess to what extent inherited antithrombin deficiency contributes to mortality

The use of oral anticoagulation will prevent many thrombotic events, nonfatal and fatal Current guidelines for individuals with antithrombin deficiency are not unitorm, especially with regard to longterm anticoagulant prophylaxis in asymptomatıc individuals This issue is important, since long-term anticoagulant treatment is also associated with a risk of disability and death from cerebral hemorrhages and other major hemorrhages $(5,6)$ So, there may even be an excess of deaths of venous thromboembolic diseases in antithrombin deficiency that is not outweighed by the risk of anticoagulant prophylaxis

\section{Methods}

Families Fourteen Dutch families with inhented antithrombin deficiency participated in this study The diagnosis was initrally based on antithrombin activity levels of less than $80 \%$ of normal, but since then many underlyng genetic defects have been identified (7) In 2 familes a heparn binding defect was found and in 9, a defect underlying type I antithrombin deficiency In 3 families with type I deficiency phenotype, a defect has not yet been identified

We used municipal population records and state archives to complete the pedigrees and to obtain information on date of birth, date of death and the death certificates We restricted our study population to those who were deficient with certanty and those who had a Mendelian probability of 05 of carriership of the defect These genetic probabilities greater than or equal to 05 could be assigned in the pedigrees following Mendelian rules since antithrombin deficiency is a dominant autosomal disorder with a low rate of new mutations All first degree famly members of carriers were assigned a probablity of 05 , regardless of the test results This was done to avord bras by excluding individu- 
als who had died prematurely and therefore could not be tested. Hence, we included complete sibships in the analysis. We used the test results to include new generations with 0.5 probability. Follow-up extended from the date of birth to December 31, 1994 or the date of death.

The causes of death could be obtained for the period 1940 to 1994. On the death certificates multiple causes are included, coded by specialized physicians of the Netherlands Central Bureau of Statistics using the International Classification of Diseases, Injuries and Causes of Death, Fifth to Ninth Revision (8, 10-13). For each death, an underlying ('primary') cause of death and any other contributing ('secondary') causes to a maximum of three are assigned ( 9 ).

We divided the causes into 7 categories: malignant neoplasms (ICD-9 codes 1400-2089), circulatory diseases (ICD-9 codes 3900-4599), cerebrovascular diseases (ICD-9 codes 4300-4389), ischemic heart diseases (ICD-9 codes 4100-4149), respiratory diseases (ICD-9 codes 4600-5199), pneumonia (ICD-9 codes 4600-4680), and thromboembolic complications. We included in the thromboembolic category the codes for "pulmonary embolism" (ICD-9 code 4151), "phlebitis and thrombophlebitıs" (ICD-9 codes 4510-4519), "other venous embolism or thrombosis" (ICD-9 codes 4530-4539), "venous complications in pregnancy and puerperium" (ICD-9 codes 6710-6719), and "obstetrical pulmonary embolism" (ICD-9 codes 6730-6739) as they are the most common venous thromboembolic complications in the general population. We assigned the ICD-codes and recoded the older ICD-codes following the Ninth Revision $(8,10-13)$.

For the primary causes of death we obtained from the Netherlands Central Bureau of Statistics the mortality rates or annual total number of deaths from which the rates could be computed for 1940 to 1994. Population mortality rates for secondary causes have been recorded by The Netherlands Central Bureau of Statistics from 1950 onwards.

Analysis. We calculated standardized mortality ratios (SMRs) as the ratio of the number of observed deaths in our study population to the expected number of deaths in the general population, i.e. the number of deaths that would have occurred according to the mortality rates of the general population adjusted for age, sex and calendar period. SMRs were calculated for overall mortality between 1830 and 1994; cause-specific SMRs from 1940 for underlying disorders and from 1950 for contributing disorders using the computer program 'Person-Years' (14). The calendar periods were divided into 20-year intervals for 1830 to 1900 , ten-year intervals for 1900 to 1940 and five-year intervals for 1940 to 1994. To calculate the expected number of deaths for each of these periods, we used the population mortality rates of the mid-interval year subcategorized into five year age groups and by sex.

In 2 families it could not be determined who had been the original probands and so we counted 12 probands. To eliminate bias that may have led to a falsely low SMR, we omitted person-years of the following subjects in our study cohort: probands were included only from the date of diagnosis; individuals, whose test results were used to extend a pedigree, entered the study at the date of birth of their first child. The rationale is that, in retrospect, probands could

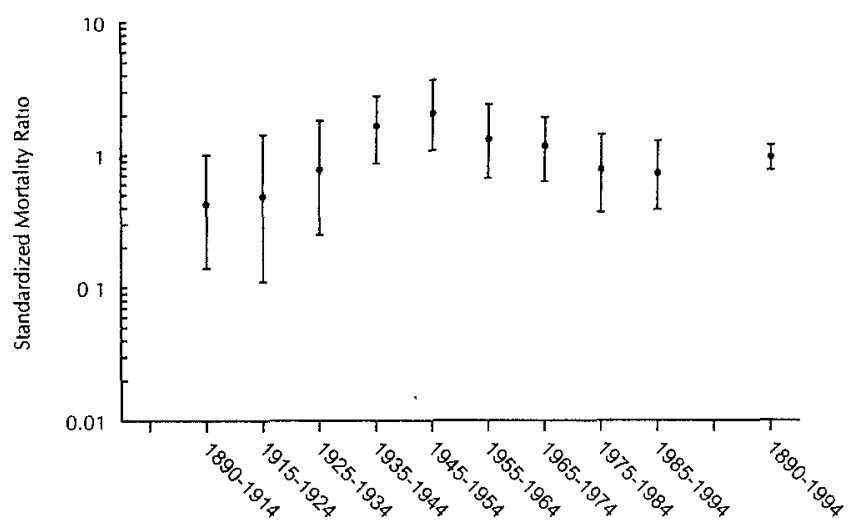

Fig. 1 Mortality rates in families with inherited antithrombin deficiency by calendar period from 1890 to 1994 (as the year of death ranged from 1890 onwards) not have died before the date of diagnosis, and persons who transmitted the gene could not have died before the age of procreation. All other individuals entered the study at the date of birth. Given the uncertainty about mortality data for children $<1$ year old. we omitted the first year of life of the subjects of our study cohort both for observed and expected deaths. Confidence intervals were calculated based on a Porsson distribution for the observed number of deaths (15).

\section{Results}

In 14 families, followed from 1830 to 1940, 266 individuals were investigated. From their dates of entry 146 men and 120 women lived a total of 11210 person-years (all ages combined). The smallest family contributed 5 individuals to the study group and the largest, 53. In the families the number of generations varied between 2 and 6 . Two families with antithrombin deficiency type II $c$ were included, together comprising 12 individuals. A total of 11 subjects emigrated during follow-up and were censored at the emigration date.

During follow-up 86 individuals died, whereas a total of 95.9 deaths would have been expected in a hypothetical cohort of the general population with the same sex and age distribution (SMR $=0.90,95 \%$ C.I. 0.72-1.11). Thus, from 1830 to 1994 overall mortality was not increased. The SMR for men was 0.96 (58 deaths, $95 \%$ C.I. 0.73-1.25) and for women 0.79 (28 deaths, 95\% C.I. 0.53-1.15). Figure 1 shows the mortality rates for the various calendar periods from 1890 onwards.

From 1940 to 1994 all-cause SMR was 1.09 with no differences between men and women ( 44 deaths in men, SMR $=1.20 ; 95 \%$ C.I. $0.87-1.61 ; 22$ deaths in women, $\mathrm{SMR}=0.92 ; 95 \%$ C.I. $0.58-1.39$ ). For this period the most frequent causes of death are listed for 58 individuals in Table 1. The underlying cause of death could not be retrieved from death certificates in 8 cases: 2 subjects died in World War II; 2 died abroad and for 4 individuals we could not get hold of death certificates from the municipal records.

Table 1 Observed number of deaths, and SMR for different causes between 1940 and 1994

\begin{tabular}{lccc} 
Cause of death & $\begin{array}{c}\text { Number of deaths } \\
\text { Observed }\end{array}$ & SMR & $95 \%$ C.I. \\
\hline All causes & 58 & 1.00 & $0.76-130$ \\
men & 39 & 111 & $079-151$ \\
women & 19 & 0.84 & $0.51-132$
\end{tabular}

Neoplasms

Malignant neoplasms

$0.90 \quad 0.49-151$

Circulatory diseases

All"

Cerebrovascular diseases

28

$1.180 .79-1.71$

$0.87 \quad 0.28-2.03$

Ischemic heart disease

$1.120 .60-1.92$

Thrombo-embolic diseases

13

$3.23 \quad 0.08-18.00$

Respiratory diseases

$\mathrm{All}^{+}$

Pneumonia

$1.68 \quad 068-3.47$

$286 \quad 0.78 \cdot 7.32$ 
Venous thromboembolism was listed only once as a primary cause: pulmonary embolism in puerperium in a 30 year old woman. Since we expected 0.31 deaths for venous thromboembolism as primary cause, this led to a SMR of 3.23 (95\% C.I. 0.08-18.00).

Most deaths ( $42 \%$ ) were classified as caused by circulatory diseases. This mortality was similar to that in the general population; analogously, we found no excess of cancer mortality. Mortality due to respiratory diseases was slightly higher than expected. This seemed to be due to a higher mortality of pneumonia than expected. Chronic respiratory diseases were responsible for 3 other deaths in this category.

For overall cerebrovascular diseases we found no excess mortality. This group consisted of 3 cerebral hemorrhages, occlusion of the cerebral arteries due to thrombosis in one patient, and an ill-defined vascular lesion which could have been either hemorrhagic or thrombotic of origin in one patient.

Other causes ( 9 deaths) included diseases of the central nervous system (3 deaths), digestive system (3 deaths), urogenital system (1 death). Two deaths were classified in the category 'Symptoms, signs and ill defined conditions'. We obtained information from the family that a fatal pulmonary embolism had been the cause of one of these two deaths, a 20 year old man without a specific acquired risk factor. In total, therefore, venous thromboembolism contributed to 2 deaths, cerebral hemorrhages to 3 deaths and occlusion of cerebral arteries to one or possibly two deaths.

To investigate whether thrombosis could have contributed to more deaths without having been listed as the primary cause, we obtained information of 32 secondary causes from 1950 onwards. As secondary cause we expected 1.14 deaths for venous thromboembolism but observed none (Table 2). Circulatory diseases (15 deaths) and respiratory diseases (6 deaths) were the most frequent secondary causes. Cerebrovascular diseases as secondary cause included 3 cases of cerebral thrombosis and embolism, 1 occlusion of precerebral arteries and 2 illdefined vascular lesions, which could have been either hemorrhagic or thrombotic in origin. The primary causes given in these cases were chronic nephritis (1 death), cholecystitis (1 death) and ischemic heart disease ( 4 deaths).

Table 2 Observed and expected number of deaths from thrombosis-related causes between 1940 and 1994

$\begin{array}{ll}\text { Thromboembolic complications } & \text { Number of deaths } \\ \text { Observed Expected }\end{array}$

$\begin{array}{lll}\text { As primary cause } & 031 \\ \text { Pulmonary embolism } & - & 0.14 \\ \text { Venous thrombosis } & - & 0.10 \\ \text { and thrombophlebitis } & & \\ \text { Of the puerperium } & 1 & 0.07 \\ & & \\ \text { As secondary cause } & - & 1.14 \\ \text { Pulmonary embolism } & - & 0.91 \\ \text { Venous thrombosis } & - & 0.23 \\ \text { and thrombophlebitis } & \end{array}$

Of the puerperium $\quad-\quad 0.00$
The mean age of death (all causes) was 61 years (range 2-88) in men, 69 years (range 30-83) in women and altogether 64 years. The one thromboembolic complication in pregnancy led to the youngest death among women. In men other causes (digestive system, central nervous system) led to death at a young age. However, the fatal pulmonary embolism coded as an "ill defined and unknown" cause of death occurred in a young man aged 20 . The mean age of death from respiratory diseases was 79 years (range 64-88) in men and 64 years in women. For cerebrovascular diseases it was 73 years (range 61-85) in men and 76 years (range $75-77$ ) in women. It was 82 years (range $80-85$ ) for those deaths in which cerebral thrombosis contributed to mortality with circulatory diseases as primary cause, and 58 years when it contributed to the other primary causes. For the 3 cerebral hemorrhages it was 70 years (range 61-75).

\section{Discussion}

Investigation of overall mortality from a follow-up from 1830 to 1994 in 14 families revealed a normal life expectancy for individuals with $\geq 0.5$ probability of heterozygosity for inherited antithrombin deficiency. As this finding is not necessarily in conflict with higher mortality specifically due to venous thrombosis, we compared the cause-specific mortality in these families with that of the general population. A venous thromboembolic complication was listed only once as the primary cause of death and was suspected in another death listed as "ill defined".

Although two venous thromboembolic complications is higher than expected for this cohort, it does not indicate that inherited antithrombin deficiency in these families is associated with a high rate of mortality due to thrombotic causes. Even including the total number of primary and secondary causes expected for venous thromboembolic complications ( 1.45 deaths), the two deaths do not immediately raise much concern. One fatal pulmonary embolism occurred during puerperium. In women venous thrombosis often manifests with pregnancy, puerperium or the use of oral contraceptives (16). However, we did not find a sex difference in overall mortality.

No large studies have investigated mortality and causes of death for inherited antithrombin deficiency before, and fatal thromboembolic episodes have been reported in some cases or pedigrees (2). Our results suggest now that those are rare occurrences, and suggest publication or detection bias in these previously published case reports or pedigree studies.

Oral anticoagulant treatment will prevent many thromboses. Longterm antithrombotic prophylaxis reduces the incidence of recurrent episodes, and when short-term prophylaxis is recommended in asymptomatic individuals in high-risk situations, a positive effect on morbidity is seen (16-17). As for mortality, we may conclude that no further improvement of survival is to be expected from long-term anticoagulation in asymptomatic individuals. Moreover, since fatalities due to thrombotic episodes remain rare, prevention of these episodes with long-term anticoagulation in asymptomatic individuals is not indicated because of the greater risk of induced fatal bleeding. Previously, we estimated this risk to be 0.6 per 100 treatment years (6).

In this study the fatal thrombotic complications, although few, were dramatic since they manifested at a young age. The postpartum death in a women aged 30 years might have been prevented by a policy of giving anticoagulation for a short period around and after delivery, which is now common practice in antithrombin deficiency. The other death, as far as we know, occurred outside of any risk situation in a man aged 20 years, and therefore might only have been prevented by a policy of 
Indiscriminate long-term prophylaxis of asymptomatıc individuals When applying the risk of fatal bleeding to the several thousand personyears, this would have led to a considerable number of hemorrhagic deaths, far outweighing the benefits

The general impression is that arterial disease is not a feature of ant1thrombin deficiency, with the exception of homozygous type IIc deficiency where venous as well as arterial thrombosis may occur at a very young age (18) We found no excess mortality for ischemic heart diseases Ischemic heart diseases are known clearly to be associated with stroke We found cerebral thrombosis and embolism mentioned four times as secondary cause with ischemic heart diseases In 2 more sub jects cerebral thrombosis (listed as a secondary cause) had contributed to death, at a slightly younger age, and the primary cause was not 1schemic heart disease One cannot exclude that similar pathogenesis of atherosclerosis in the cerebral circulation or embolism from left ven tncular thrombus complicating myocardial intarction (undiagnosed) had existed in these 2 individuals

A slightly higher mortality due to respiratory diseases seemed due to a higher mortality of pneumonia No infectious organisms were mentioned in the 4 subjects with fatal pneumonia It cannot completely be ruled out therefore that the higher mortality in this group could be explaned by misdiagnosis of one or more underlying pulmonary embolisms If this was the case, venous thromboembolic complications were somewhat underestimated However, the consequence of such an underestimate is not severe, as the mean age of death was 75 years for these indrviduals

The pattern of mortality with regard to common causes did not differ from that in the general population The comparison of causes of death was based on death certificate classifications This guaranteed a valid companson as the classification was the same for the study cohort and the general population Because we included individuals with $\geq 05$ probability of being deficient, some individuals may, in reality, have had normal antithrombin concentrations These normal individuals will have diluted any observed effect on mortality, but they cannot explain that we did not find any difference in overall and specific mortality compared to the general population

In conclusion, we found no excess mortality and no high rate of death from venous thromboembolic diseases The thrombotic fatalities that were observed developed at a relatively young age, one in association with a well known risk situation, but their number did not greatly exceeded the expected number for these occurrences With a greater risk of bleeding than the risk of fatal thromboembolic complications long-term anticoagulant treatment cannot be recommended for asymptomatic individuals

\section{Acknowledgements}

We thank the Department of Health Statistics of the Netherlands Central Bureau of Statıstics in Voorburg, The Netherlands for generously makıng avalable the mortality statistics and database linkıng

\section{References}

1 Hirsh J, Piovella F, Pinı M Congental antıthrombin III deficiency Incı dence and clinical features Am J Med 1989, 87 34S 8S

2 De Stefano V, Leone G Mortality related to thrombosis in congental ant1 thrombin III deficiency (letter) Lancet 1991 3378478

3 Rosendaal FR, Heljboer H, Bret E, Buller HR, Brandjes DPM, de Brum K, Hommes DW, Vandenbroucke IP Mortality in hereditary antithrombin-III deficiency 1830 to 1989 Lancet 19913372602

4 Allaart CF Rosendaal FR Noteboom WMP Vandenbroucke JP, Brset E Survival in familes with hereditary protein C deficiency, 1820 to 1993 BMJ 1995,3119103

5 Levine MN, Raskob G, Hirsh J Hemorrhagic complications of long term anticoagulant therapy Chest 198995 26S 36S

6 van der Meer FJM Rosendaal FR Vandenbroucke JP Briet E Bleedıng complications in ord anticoagulant therapy An analysis of risk factors Arch Intern Med 1993, 153 1557-62

7 van Boven HH, Olds RJ Thein SL, Retsma PH Lane DA Briet E, Vandenbroucke JP Rosendaal FR Hereditary antithrombin deficiency heterogeneity of the molecular basıs and moitality in Dutch tamilies Blood 1994 84420913

8 World Health Organization Manual of the International Statıstical Classif cation of Disease, Injuries and Causes of Death Ninth Revision Geneva World Health Organızation, 1977

9 Mackenbach JP, Kunst AE Lautenbach H, Bılsma F Oeı YB Competıng causes of death an analysis using multiple cause of death data from the Netherlands Am J Epıdemıl $1995141 \quad 466-75$

10 Centraal Bureau voor de Statıstiek Groote internationale lıjst van doodsoorzaken 1938 's Gravenhage Centraal Bureau voor de Statıstiek 1940

11 World Health Organization Manual of the International Statıstical Classification of Disease, Injurres, and Causes of Death Sixth Revision Geneva World Health Organization, 1948

12 World Health Organizatıon Manual of the International Statistical Classif 1 cation of Disease, Injurses, and Causes of Death Seventh Revisson Gene va World Health Organization, 1957

13 World Health Organization Manual of the International Statıstical Classifi cation of Disease, Injuries, and Causes of Death Eighth Revision Geneva World Health Organization, 1968

14 Coleman M, Douglas A, Hermon C, Peto J Cohort study analysıs with a FORTRAN computer program Int J Epidemıl 1986151347

15 Breslow NE, Day NE Rates and rate standardization In Statıstical methods in cancer research Volume II - The design and analysis of coholl studies International Agency for Research on Cancer (IARC Scientific publications no 82) Lyon 1987 pp 69-72

16 De Stefano V, Leone G Mastrangelo S, Tripodı A Rodeghıero F Casta man G, Barbuı T, Finazzı G, Bızzı B, Mannuccı PM Clincal manıfesta tions and management of inherted thrombophilia retrospective analysis and follow-up after diagnosis of 238 patients with congental deficiency of antithrombin III, protem C, protein S Thromb Haemost 1994, 72 352-8

17 Demers C, Ginsberg JS, Hirsh J, Henderson P, Blajchman MA Thrombosis in antithrombin-III deficient persons Report of a large kindred and litera ture review Ann Intern Med 1992, 11675461

18 Chowdhury V, Lane DA, Mille B, Auberger K, Gandenberger-Bachem S Pabinger I, Olds RJ, Thein SL Homozygous antthrombin deficiency re port of two new cases (99 Leu to Phe) associated with arterial and venous thrombosis Thromb Haemost 1994, 72198202

Received July 25, 1996 Accepted after revisıon November 151996 